\title{
The Impact of Hydrothermal Treatments on Technological Properties of Whole Grains and Soriz (Sorghum oryzoidum) Groats
}

\author{
Rodica Siminiuc ${ }^{1,2 *}$, Dinu Țurcanu ${ }^{2,3}$ \\ 1Food and Nutrition Department, Chisinau, Republic of Moldova \\ 2Technical University of Moldova, Chisinau, Republic of Moldova \\ 3Informatization, Partnerships, Institutional Image and Communication Office, Chisinau, Republic of Moldova \\ Email: *rodica.siminiuc@adm.utm.md, dinu.turcanu@adm.utm.md
}

How to cite this paper: Siminiuc, R. and Turcanu, D. (2020) The Impact of Hydrothermal Treatments on Technological Properties of Whole Grains and Soriz (Sorghum oryzoidum) Groats. Food and Nutrition Sciences, 11, 955-968. https://doi.org/10.4236/fns.2020.11100 $\underline{67}$

Received: September 11, 2020

Accepted: October 24, 2020

Published: October 27, 2020

Copyright (C) 2020 by author(s) and Scientific Research Publishing Inc. This work is licensed under the Creative Commons Attribution International License (CC BY 4.0).

http://creativecommons.org/licenses/by/ $4.0 /$

(c) (i)

Open Acces

\begin{abstract}
Cereals and cereal products are the basic element in ensuring the food security of the population. Most cereal-based foods contain gluten. Nutritional therapy is the only treatment for people with gluten-related disorders. No gluten-free products are manufactured in the Republic of Moldova, and the imported ones are sold at very high prices. In this context, Moldova is an unexplored field and research is required. The paper investigated the impact of hydrothermal treatments on whole grains and sorghum groats. It was found that whole grains and sorghum groats have a cooking time of about 130 and 40 minutes, respectively, which can be reduced by about 2 times by prior hydration in water. Hydration media and their concentrations ( $\mathrm{NaCl}$ solutions; sol. $\mathrm{NaHCO}_{3}$ and $\mathrm{C}_{6} \mathrm{H}_{80}$ concentrations $0.5 \% ; 1.0 \%$ and $2.0 \%$ ) differently influence the cooking time, mass, volume and firmness of the grains.
\end{abstract}

\section{Keywords}

Hydrothermal Treatment, Culinary Properties, Soriz (Sorghum oryzoidum), Whole Grains, Firmness, Gluten Free

\section{Introduction}

Cereals and cereal products are the basic element in ensuring the food security of the population. The World Health Organization recommends that most energy come from cereals. Increasing the consumption of cereals, especially whole grains, is an important goal, thanks to its protective role against diabetes and other metabolic diseases, as well as against cancer [1].

Although nutritional trends in recent decades have shifted to whole grains, refined cereals, especially white flours and white bread assortments, are often 
preferred to whole grain foods due to the general desire of consumers to benefit from quality products high volume, which led to the selection of wheat varieties with high gluten content to obtain voluminous products with high porosity and long-term freshness [2].

Consequently, today we are facing a rising epidemic of gluten-related disorders such as celiac disease, allergy and gluten sensitivity [3]. They are characterized by atrophy of the epithelium of the small intestine and by malabsorption resulting from this phenomenon [4]. As a result, celiac disease can cause growth retardation, infertility, anemia, stomatitis, dermatitis, hypocalcemia, etc. People who show disorders related to gluten consumption, are forced to follow a gluten-free diet, which may have different weight, depending on the specific conditions of the disease [5]. Gluten-free products are an example of reverse functional foods, in which gluten is excluded and not included, like other constituents. In fact, gluten-free products are currently an area in full swing, and the main representatives are cereals and cereal derivatives [6].

\subsection{Soriz (Sorghum oryzoidum) -Perspective Grain for the Republic of Moldova}

Soriz (Sorghum Oryzoidum) is a hybrid of sorghum obtained for the first time by the Moldovan breeder Gheorghe Moraru during research conducted in 1987-1988 at the Institute for Scientific Research for Corn and Sorghum (The Image 1(a), Image 1(b)) [7].

Starting with 2010, research on the cultivation and capitalization of sorghum hybrids is carried out at the Institute of Plant Protection and Organic Agriculture of the Academy of Sciences of Moldova. The advantages of soriz cultivation are manifested in the production process, which does not require major investments: the plant is not pretentious to soil conditions, fertilizers and has tolerance to diseases and pests. It has high productivity per hectare: in favorable conditions the productivity of soriz reaches 6 - 8 ton per hectare, and in 2012, in the northern parts of the republic (Briceni) the harvest reached 12 ton per hectare. In Russia, Ukraine and the Republic of Moldova, the capitalization of this culture has aroused the interest of specialists in various fields.

Technologies for primary processing of soriz were developed, the physicochemical, hygroscopic, biochemical properties and thermophysical characteristics were studied, as an object for drying and storage. Technologies have been developed for the production of sorghum grains in order to obtain flakes. According to scientific research institutions and trade organizations in the Republic of Moldova, Ukraine and Russia, the nutritional value of soriz beans is at the level of rice grains and can be successfully used in the production of a wide range of basic foodstuffs for humans [8]. Previous research on the chemical composition of soriz reveals a content of: starch-74.12\% - 82.0\%/dry matter (d.m), protein-about 13.0\%/d.m., sugars-0.24\% - 0.37\%/d.m., lipids $-0.1 \% \ldots .5 \%$ d.m., ash $-0.36 \%-2.0 \% /$ d.m. In the whole grain of soriz

$\begin{array}{lllllllllll}\mathrm{t} & \mathrm{h} & \mathrm{e} & \mathrm{d} & \mathrm{o} & \mathrm{m} & \mathrm{i} & \mathrm{n} & \mathrm{a} & \mathrm{n} & \mathrm{t}\end{array}$




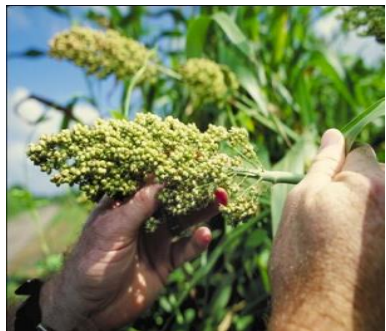

(a)

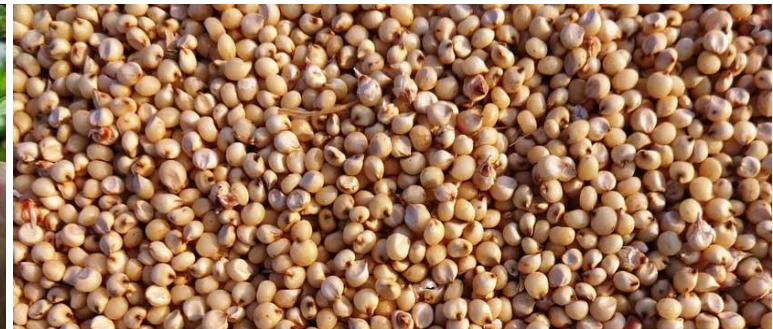

(b)

Image 1. (a) Panicle of soriz (Sorghum oryzoidum); (b) Whole grains of soriz (Sorghum oryzoidum).

protein fractions belong to prolamins ( $56.0 \%$ of the total protein), followed by gluteline (22.4\%), globulins (7.3) and albumin (6.7) [9].

\subsection{The Importance of the Research}

The World Health Organization recommends the widespread use of cereal-based foods in strengthening the health potential of the population. The valorization of the soriz in food will allow the diversification of the assortment of local cereal products and will increase the food security of the population in the Republic of Moldova. Research on the belonging of soriz to the group of glutenfree cereals is up to date. The elaboration of gluten free foods based on ingredients derived from Sorghum Oryzoidum grains for those suffering from gluten intolerance and malabsorption, as well as for healthy people, will allow the use of local resources in the production of functional foods with a curative role.

\subsection{The Objective of the Research}

The aim of this study was to investigate the impact of boiling in different media (distilled water, salt solutions, basic solutions and food acid solutions) on the consistency of whole soriz grains and groats in order to establish the optimal heat treatment conditions, which ensures their acceptable palatability.

\section{Materials and Methods}

The culinary technological properties of grains and cereals refer to their ability to boil in the shortest possible time, accompanied by improved organoleptic qualities. Prior to the culinary treatment, the cereals are subjected to technological processes of primary processing such as: sorting (sometimes sifting) and washing. After sorting and washing in cereals, a considerable amount of water $(10 \%-30 \%$ of the mass of the groats) is retained, which must be taken into account when calculating the ratio of water: boiling product. The content of dry substances in the water after washing reaches the following weight: starchabout $41 \%$, nitrogenous substances-about $33 \%$ and sugar-about $13 \%$ [10].

\subsection{Materials}

As main raw materials for research were used: 
- Whole grains of soriz (Pișcevoi-1);

- Soriz groats (obtained by peeling);

The raw material was purchased from the Institute of Plant Protection of the Republic of Moldova

\subsection{Methods}

The culinary preparation technology of cereals considerably influences their nutritional value. The most used culinary treatment process for cereals is boiling. Boiling is a hydrothermal process, which includes the simultaneous action of temperature and water and is part of the category of processes with heat transfer for food preparation [11]. Usually, the culinary value of cereals is characterized by:

- cooking time (in minutes);

- increasing the volume and mass of grains/groats by boiling;

- the coefficient of boiling by mass $(\mathrm{Km})$ and volume $(\mathrm{Kv})$;

- determining the stability of the grains/groats by boiling;

- organoleptic characteristic of boiled grains and/or groats.

\subsubsection{Boiling Time}

To determine the cooking time, the whole grains and soriz grains (obtained by dehulling the grains) were boiled in distilled water, over medium heat, until penetration. At time intervals, by crushing the grains between two glass slides, the presence of non gelled starch particles was checked inside the grains.

\subsubsection{The Process of Hydrating Whole Grain Grains}

The relatively long time for boiling whole grains of soriz creates economic, technological and nutritional disadvantages. In order to reduce the cooking time, the whole grains were subjected to hydration in neutral, acidic and basic aqueous solutions of different concentrations for 24 hours. $40 \mathrm{~g}$ of whole soriz grains were placed in $200 \mathrm{ml}$ of saline, acid and alkaline solutions of various concentrations for hydration, at a temperature of $20^{\circ} \mathrm{C} \pm 2^{\circ} \mathrm{C}$. The weight gain of the grains was determined at set intervals of time, by withdrawing the grains from the water. After reaching the required soaking time, the sample was drained on a paper napkin and the excess water was removed with filter paper.

\subsubsection{Determination of Firmness of Sorghum Grains and Croups}

The structo-textural firmness of boiled chickpeas was determined with the F2 laboratory finometer (Kohusz, Hungary) [12]. Its working principle is based on the indication of the maximum penetration pressure of boiled chickpeas by a piston with several punches, which come into contact with the product. The maximum penetration force in units or degrees of the finometer $\left(\mathrm{F}^{\circ}\right)$ is read on the dial of the device. In order to determine the firmness of the grains after the specific treatments (hydration in various media and concentrations, boiling), they were introduced into the finometer container. A cooking time limit of 150 
minutes has been set. At 30-minute intervals, the grains were extracted from the boiling medium, drained of excess moisture and allowed to cool to room temperature.

\section{Results and Discussion}

The cooking time of the soriz groats was $35 \pm 5$ minutes, and of the whole grains of soriz was 130 (130 \pm 10 minutes $)$.

\subsection{The Effect of Hydration of Whole Soriz Grains on Technological Properties}

\subsubsection{Modification of the Mass and Volume on Hydration}

The hydration of the grains is conditioned by the anatomical structure of the grain and the unilateral diffusion of water inside the grains, which hydrates the polar sectors of the grain macromolecules and as a result, the flexible molecules distance each other, the bond between them weakens and the mass increases [13]. A more intense increase in mass is observed in the first two hours of hydration (by 15\% - 18\%), after which the increase in mass takes place more slowly (by another 15\% in an interval of 6 - 8 hours) (Figures 1(a)-(c)).

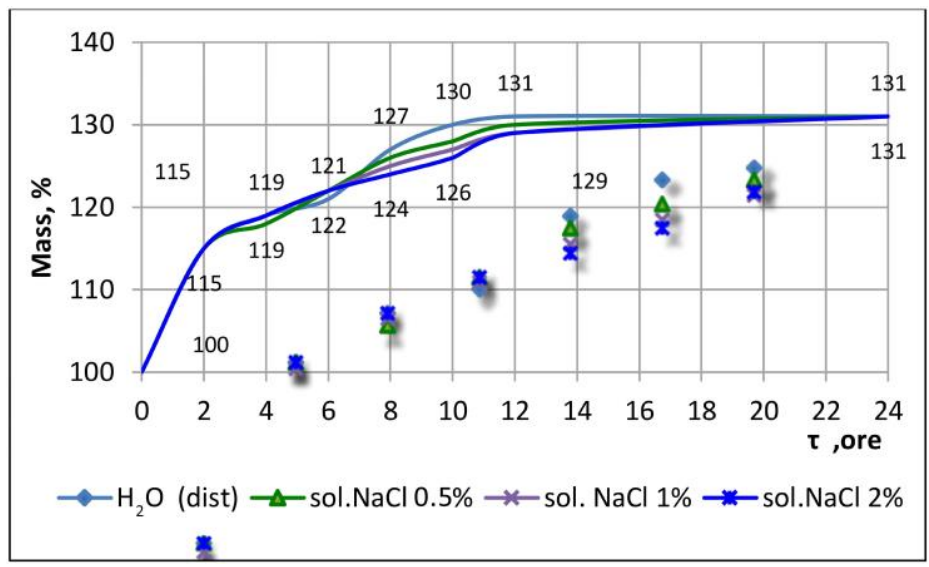

(a)

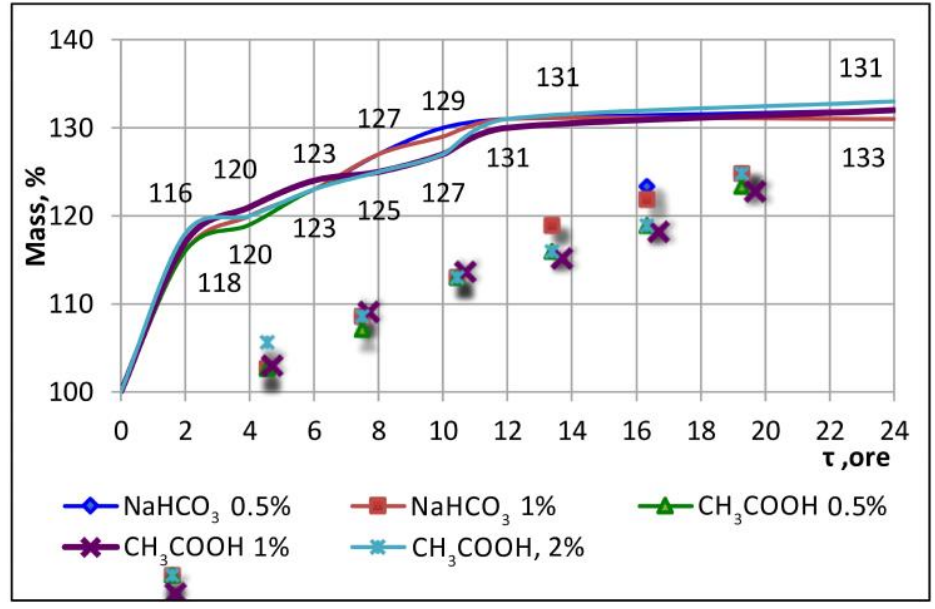

(b) 


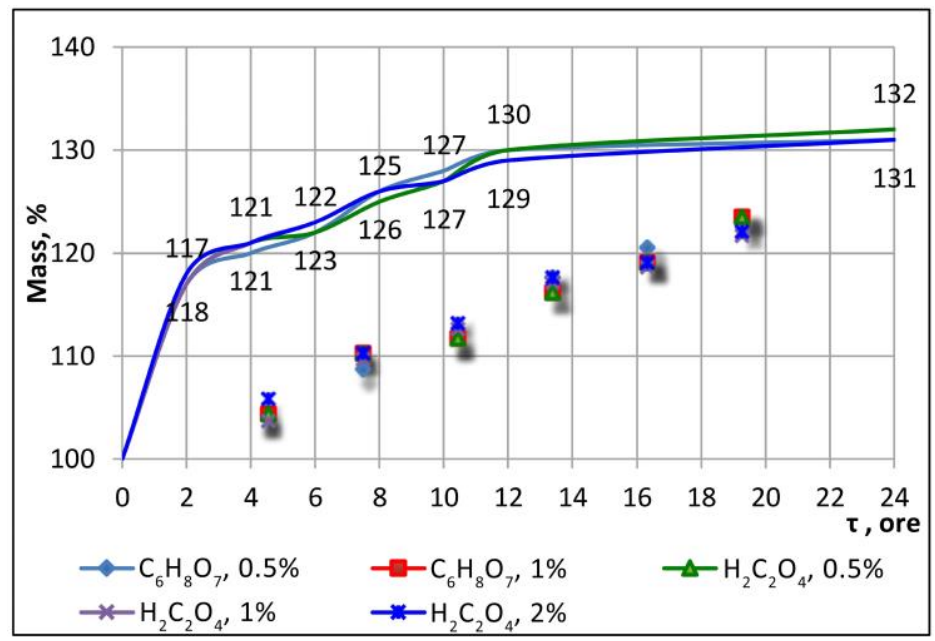

(c)

Figure 1. (a) Modification of the mass of whole soriz grains by hydration in water and sodium chloride; (b) Modification of the mass of whole soriz grains by hydration in sodium bicarbonate and acetic acid; (c) Modification of the mass of whole soriz grains on hydration in oxalic acid and citric.

For wheat, for example, grain moisture, one hour after hydration increases by $12.1 \%-14.8 \%$, and in the next 12 hours-by $25.6 \%-29.5 \%$. This is due to the absorption of water at the initial stage by the membranes of the grains, which contain several capillaries, pores and voids, which serve as reservoirs for the accumulation of moisture. Subsequent water absorption takes place in the endosperm where the rate of absorption slows down [10]. After 12 hours of hydration, the mass of sorghum grains practically did not change, reaching final values of $131 \%-132 \%$ for all the researched samples, and the moisturizing agent did not essentially influence the evolution of the mass of sorghum grains. The results obtained allowed the establishment of the optimal hydration time, which is 8 - 10 hours, a period equivalent to that recommended for brown rice, but shorter than the hydration period of corn (48 hours) [14].

\subsubsection{The Influence of Hydration Media on the Cooking Time of Sorghum Grains}

After 8 - 10 hours of hydration, the sorghum grains were removed from the hydration media and boiled in distilled water until full penetration. During the boiling period, at established time intervals, the evolution of the mass and volume of the grains was analyzed, and subsequently the coefficient of boiling was calculated by mass and volume. The concentration of hydrating media did not essentially condition the boiling time, which was however slightly lower for hydrated grains in environments with low concentrations $(0.5 \%)$. The nature of the hydration media conditioned the boiling time differently: for the hydrated grains in distilled water and sodium bicarbonate solution it was about $75 \pm 5$ minutes, for those hydrated in sodium chloride and citric acid-85 \pm 5 minutes, and in oxalic and acetic acid $-95 \pm 5$ minutes (Figure 2). 


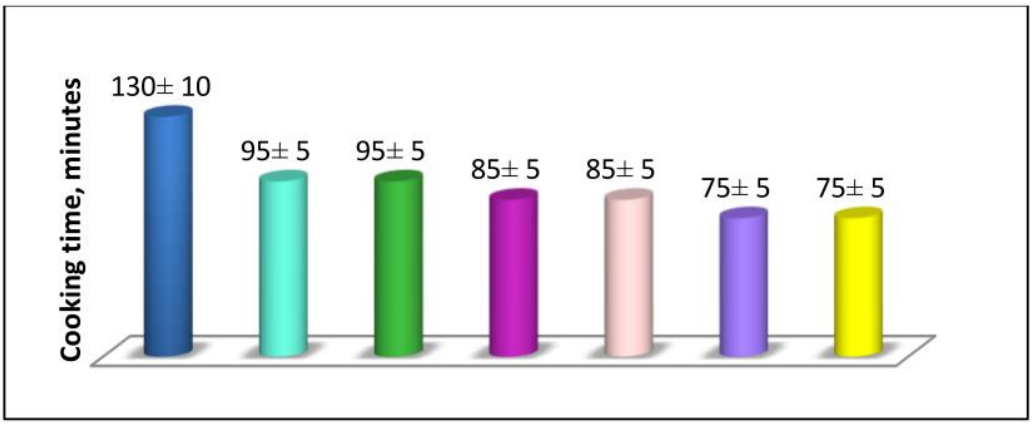

Figure 2. Boiling time of hydrated whole soriz grains in various environments (1-grain boiled without hydration; 2-grains boiled after hydration in $\mathrm{H}_{2} \mathrm{O}$; 3-grains hydrated in $\mathrm{HCl}-0.5 \%$; 4-grains hydrated in $\mathrm{NaHCO}_{3}-0.5 \%$; 5 grains hydrated in $\mathrm{CH}_{3} \mathrm{COOH}-0.5 \%$; 6-grains hydrated in $\left.\mathrm{C}_{6} \mathrm{H}_{8} \mathrm{O}_{7}\right)-0.5 \%$; 7 grains hydrated in $\mathrm{H}_{2} \mathrm{C}_{2} \mathrm{O}_{4}-0.5 \%$ ).

Pre-hydration of soriz grains in neutral, saline and basic environments reduced the cooking time by about 2 times, compared to boiled grains without hydration, and for those hydrated in organic acids-about 1.5 times.

\subsubsection{Modification of the Mass When Boiling Hydrated Whole Grains in Various Media}

The increase in temperature accelerates the process of moisture passage inside the grains, more intense hydration of protein substances and carbohydrates in the cell walls, as well as gelatinization of starch. The initial period of hydrothermal treatment is characterized by a significant increase in the destruction of cell walls, after which the process slows down. In the investigated samples the mass evolved more intensely in the first 10 - 20 minutes of boiling, especially for the hydrated grains in neutral and alkaline environments (by about $35 \%$ ), followed by the hydrated grains in sodium chloride by about $28 \%$, with $15 \%$ for those hydrated in citric acid, and for grains hydrated in acetic and oxalic acid, the increase was only $12 \%$ - 13\% (Figure 3).

In the sorghum groats, during boiling, the evolution of the relative mass and volume was more intense, compared to the whole grains, due to the loss of the hull's shell when peeling, which allowed the water to enter the grain more easily and faster. This increase is also due to the smaller size of the groats compared to the grain. In the first ten minutes of boiling the sorghum crusts, the increase of the mass was by $105 \%$, and of the volume-by $157 \%$, after which the evolution of the given indices slows down: the volume at 20 minutes increased by $71 \%$, at 30 minutes-by another $58 \%$ and after 50 minutes of boiling the final volume was $450 \%$. The growth of the mass was slower, compared to the volume: at 20 minutes-it increased by $31 \%$, at 30 minutes-by another $50 \%$, and the final mass of the cooked grains after 50 minutes was $350 \%$ (Figure 4).

This is probably due to the increase in moisture jumps with the formation of microcracks (due to osmotic pressure and concentration gradient), which lead to the grain breaking into sectors. 


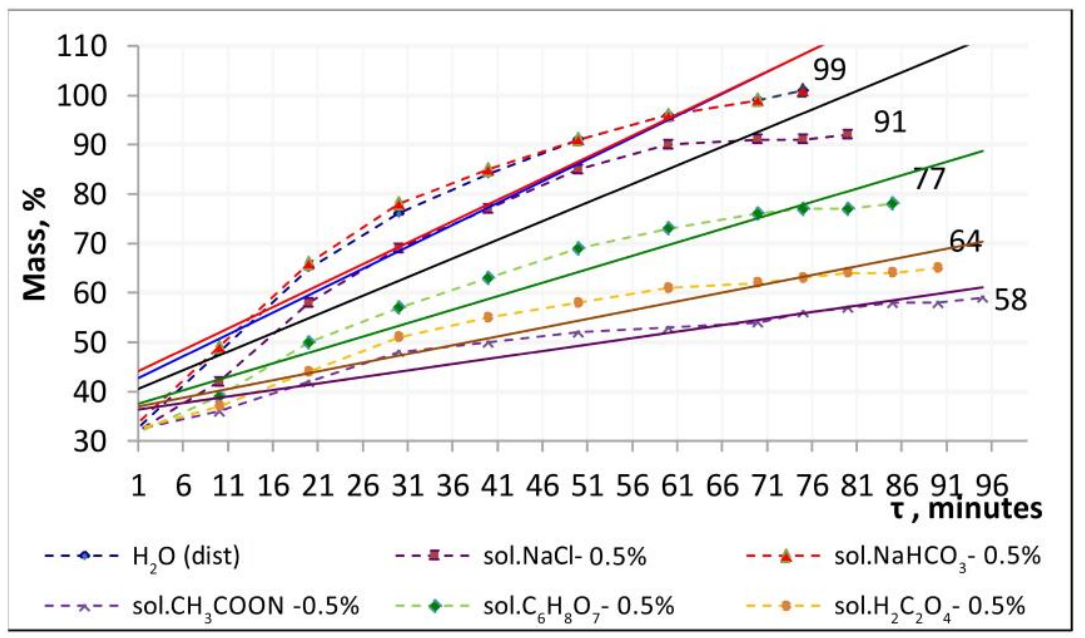

Figure 3. Modification of the mass of hydrated whole soriz grains when boiling.

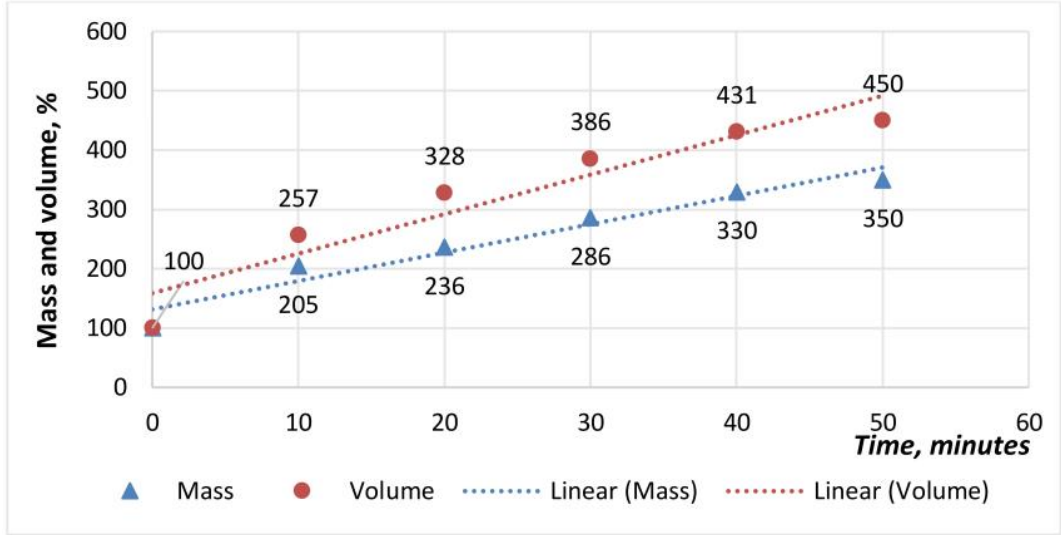

Figure 4. Modification of the mass and volume of boiled soriz groats.

\subsubsection{Coefficient of Boiling ( $\mathrm{Km}$ and $\mathrm{Kv}$ ) of Grains and Soriz Groats}

Knowing the evolution of boiling mass and volume allowed the calculation of the coefficient of boiling by mass and volume, which is one of the basic culinary indices of whole grains and derivatives. The shorter the cooking time and the higher the cooking coefficient, the better the culinary properties of the groats are considered. Because during the boiling of the grains the evolution of the mass did not show significant differences compared to that of the relative volume, respectively and the coefficients of boiling after the mass and volume are practically equal. The highest coefficients have samples boiled after hydration in distilled water and sodium bicarbonate $(\mathrm{Km}=\mathrm{Kv}=2)$, followed by samples boiled without hydration $(\mathrm{Km}=1.98, \mathrm{Kv}=2)$ and those hydrated in sodium chloride $(\mathrm{Km}=\mathrm{Kv}=1.9)$. Hydrated samples in acidic environments had the lowest values ( $\mathrm{Kv}=1.58 \ldots$ 1.79) (Figure 5).

The soriz groats reached the highest values of the boiling coefficient $(\mathrm{Km}=$ $3.5, \mathrm{Kv}=4.5)$. The obtained results exceed the values of the cooking coefficient for the buckwheat groats $(\mathrm{Kv}=2.1-4.0)$ and are close to the rice groats $(\mathrm{Kv}=$ $2.8 \ldots 4.5)$. 


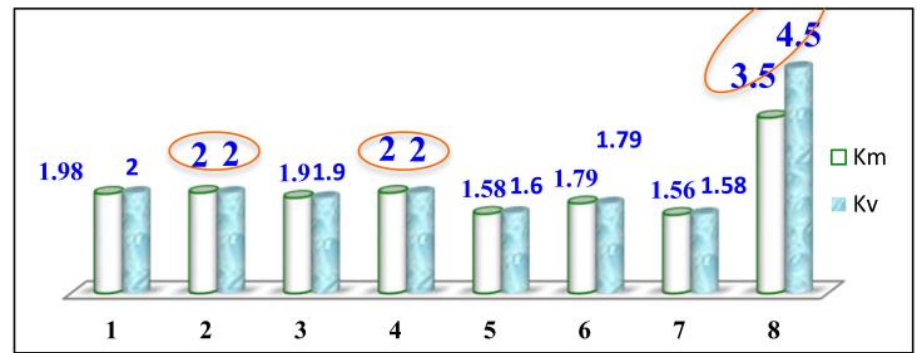

Figure 5. Coefficient of boiling (by mass and volume) of sorghum grains and groats (1-grain boiled without hydration; 2-grains boiled after hydration in $\mathrm{H}_{2} \mathrm{O}$; 3-grains hydrated in $\mathrm{HCl}-0.5 \%$; 4-grains hydrated in $\mathrm{NaHCO}_{3}-0.5 \%$; 5-grains hydrated in $\mathrm{CH}_{3} \mathrm{COOH}-0.5 \%$; 6-grains hydrated in $\mathrm{C}_{6} \mathrm{H}_{8} \mathrm{O}_{7}$ )-0.5\%; 7-grains hydrated in $\mathrm{H}_{2} \mathrm{C}_{2} \mathrm{O}_{4}-0.5 \%$; 8-boiled groats).

\subsubsection{Firmness Change}

As the turgor pressure in living plant tissues is not an important factor in most cases of technological treatment, the loss of firmness is considered a factor in the evolution of cell wall components, especially polysaccharides. However, the complexity of the composition of the plant's cell walls makes it difficult to link the texture changes and the specific chemical changes between the polysaccharides and the cell wall. After 30 minutes from the beginning of boiling, the mechanical resistance of the grains cooked without hydration was $372 \mathrm{~F}^{\circ}$, and of those hydrated in distilled water- $274 \mathrm{~F}^{\circ}$. After 90 minutes of boiling, the firmness of the first ones decreased 3 times, and of the hydrated ones 2.5 times, reaching values close to 122 and $108 \mathrm{~F}^{\circ}$ (Figure 6). Due to the prior hydration of the grains, the interaction of water with boiling protopectin and, respectively, the dissociation of protopectin in hydrated grains takes place faster than in non hydrated ones. This difference is explained by the higher humidity of hydrated whole soriz grains (due to the deeper absorption and distribution of water inside the grains in the hydration process), which led to faster tissue softening compared to cooked grains without hydration. The boiling time (about 75 minutes) of the hydrated sorghum grains, previously established, corresponds to a firmness equivalent to $160 \mathrm{~F}^{\circ}$. At the same time, the firmness of the cooked grains without prior hydration is about $185 \mathrm{~F}^{\circ}$. Just as hydration is accompanied by a number of phenomena, including the soaking of liquid in dry matter, the swelling of certain areas in the solid matrix, the leakage of soluble solids into the liquid medium, so it is also influenced by the previous treatment to which the solids have been subjected [13]. In the case of soriz groats, which have been subjected to a mechanical abrasion treatment (loss of grain cover, decrease in grain size) the reduction of firmness has them faster. Due to the removal of the coating in the peeling process, the water diffuses in the groats more intensely than in the whole grains, hydrating the polar sectors of the macromolecules and leading to softening the grain structure and changing the consistency [15]. The firmness (mechanical strength) of the soriz groats 10 minutes after the start of boiling was $220 \mathrm{~F}^{\circ}$ and decreased practically 2 times 
after 20 minutes, and at the interval of 30 - 40 minutes (the cooking time of the soriz groats) of 4 - 6 or in relation to the initial firmness (Figure 6).

The concentrations of the hydrating media had a different influence on the firmness of the soriz grains during boiling. Hydrated samples in $2 \%$ sodium chloride and citric acid solution underwent a more significant initial reduction in firmness compared to samples hydrated in the same solutions of lower concentrations $(0.5 \%$ - 1\%). Approximately 60 minutes after the start of boiling, the firmness of all samples hydrated in sodium chloride solution almost equaled, reaching values between $247-259 \mathrm{~F}^{\circ}$, after which the grains hydrated in $0.5 \%$ solution continue to lose more activeness in comparison with the other samples) (Figure 7).

The concentrations of citric acid solutions used for hydration led to a lower firmness of the hydrated grains in citric acid of $2 \%$ (Figure 8).

The high firmness in boiling hydrated soriz grains in acidic medium could be explained by the presence of acid, which inhibits the dissociation of ionized residues of polygalacturonic acids of protopectin, which leads to decreased solubility and strengthening of cell walls.

The hydrated grains in $2 \%$ sodium bicarbonate had a higher initial firmness $\left(696 \mathrm{~F}^{\circ}\right)$ compared to the hydrated grains in solutions of lower concentration (Figure 9). The relatively short boiling time (compared to other media) and the low firmness at the end of boiling could be explained by the ability of alkaline media to soften tissues in heat treatment, as it generates de-esterification of pectic substances with the formation of soluble products.

Comparing the firmness of all samples, depending on the hydration medium, we can say that the hydrated grains in sodium bicarbonate solution $\left(696 \mathrm{~F}^{\circ}\right)$ are harder (at the initial boiling stage-30 minutes), followed by the grains hydrated in citric acid $\left(632 \mathrm{~F}^{\circ}\right)$, sodium chloride $\left(508 \mathrm{~F}^{\circ}\right)$, and the hydrated grains in water were soaked during the fastest boiling. After one hour of boiling, the firmness of the hydrated grains in sodium bicarbonate decreased by 2.4 times, those hydrated in citric acid -3.3 times, in sodium chloride -1.5 times.

\subsection{Organoleptic Characteristics}

The organoleptic characteristics of whole grains and soriz groats are shown in Table 1. Due to the fine taste and smell, soriz groats could be associated with a wide range of products, being similar in this respect to rice groats.

Pre-hydration is a key unitary operation in the food industry to facilitate and reduce the duration of technological treatments (germination, heat treatments, etc.) of dry (dry) products, as well as, in particular, cereals and vegetables [16]. This operation is also carried out on a consumer scale, for which the ease of cooking and speed are often of decisive importance. The quality of hydrated products is largely affected by hydration conditions. The degree and duration of hydration are important indicators of the technological quality of the dehydrated product, especially in the case of cereals. Therefore, the hydration 
process of sorghum, as in the case of other vegetables and cereals, is of obvious theoretical and practical interest [17].

Table 1. Organoleptic characteristic of boiled soriz grains and groats.

\begin{tabular}{lll}
\hline Indices & Boiled whole grains & Boiled groats \\
\hline $\begin{array}{l}\text { Color and } \\
\text { Appearance }\end{array}$ & $\begin{array}{l}\text { Creamy-yellow, with dark spots, } \\
\text { specific to whole sorghum grains }\end{array}$ & Cream-white, uniform \\
Smell & Smell pleasant, specific to smiles, without foreign sour or rancid odors \\
Taste & Pleasant, slightly sweet, specific to the smile \\
& $\begin{array}{l}\text { The consistency of the grains is soft, soft, fine, uniform, non sticky, } \\
\text { uniform, without agglomerations, } \\
\text { well-preserved shape }\end{array}$
\end{tabular}

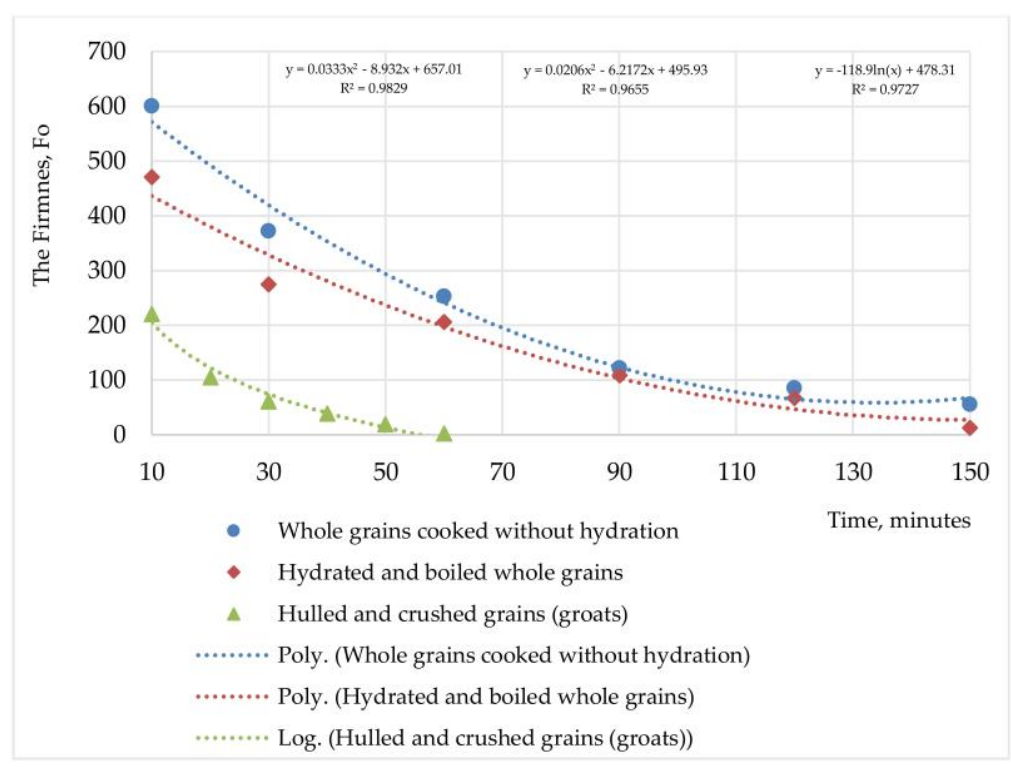

Figure 6. Firmness of hydrated and unhydrated sorghum grains and groats.

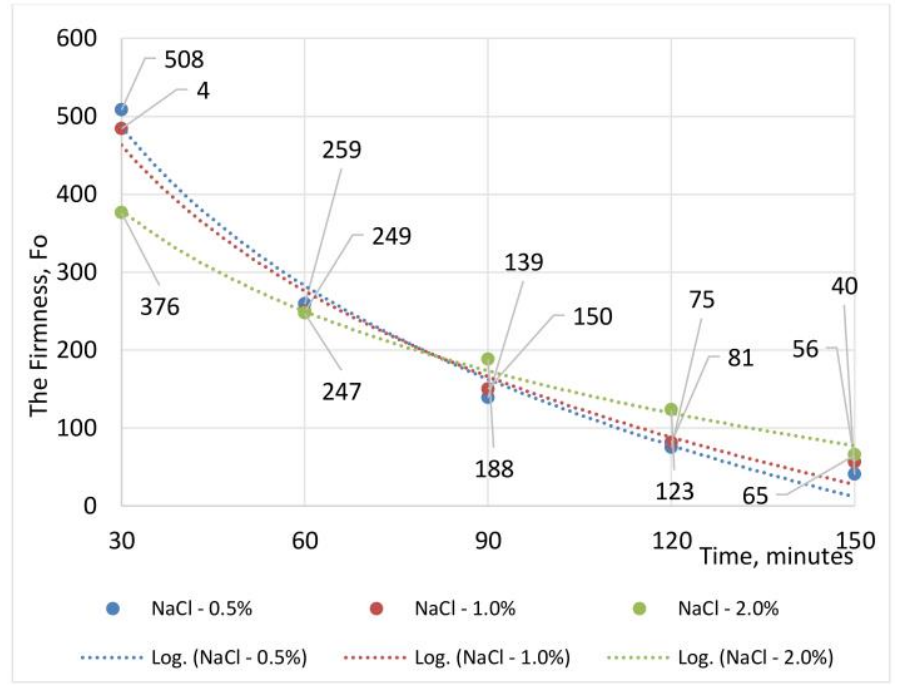

Figure 7. Firmness of boiled soriz grains after hydration in sodium chloride solutions. 


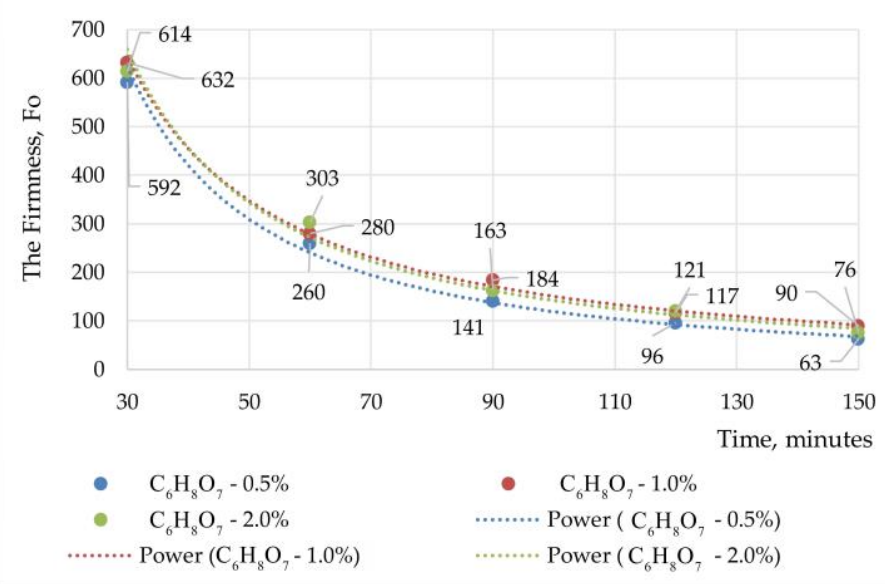

Figure 8. Firmness of hydrated sorghum grains in citric acid solutions.

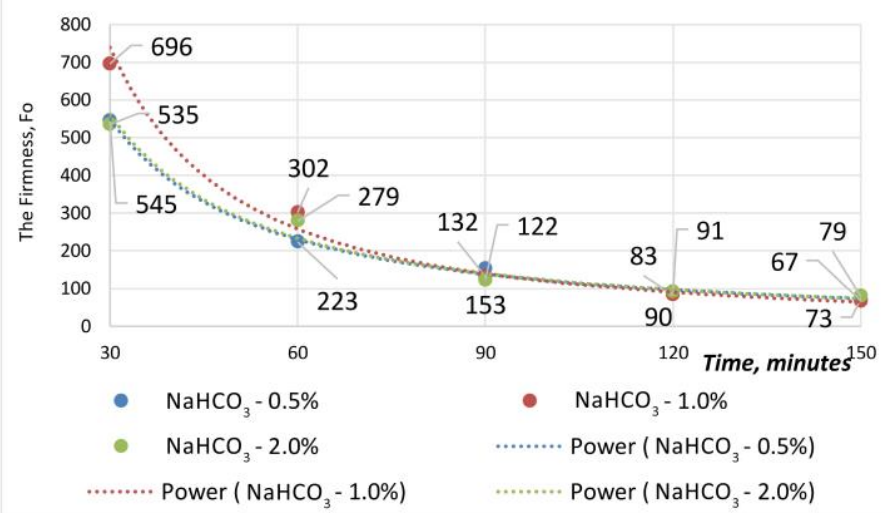

Figure 9. Firmness of hydrated soriz grains in sodium bicarbonate solution.

In the process of hydration in water or in another aqueous environment, cereals are subjected to several physico-chemical changes simultaneously, including changes in moisture and dry matter content, porosity, volume and texture. Hydration is a complex process, which includes, on the one hand, the absorption of water by the grain and, on the other hand, the leaching (extraction) of water-soluble substances from the grain in the aqueous environment [14]. Pre-hydration is a key unitary operation in the food industry to facilitate and reduce the duration of technological treatments (germination, heat treatments, etc.) of dry (dry) products, as well as, in particular, cereals and vegetables [18]. This operation is also carried out on a consumer scale, for which the ease of cooking and speed are often of decisive importance. The quality of hydrated products is largely affected by hydration conditions. The degree and duration of hydration are important indicators of the technological quality of the dehydrated product, especially in the case of cereals. Therefore, the hydration process of soriz, as in the case of other vegetables and cereals, is of obvious theoretical and practical interest [19]. In the process of hydration in water or in another aqueous environment, cereals are subjected to several physico- 
chemical changes simultaneously, including changes in moisture and dry matter content, porosity, volume and texture. Hydration is a complex process, which includes, on the one hand, the absorption of water by the grain and, on the other hand, the leaching (extraction) of water-soluble substances from the grain in the aqueous environment [10]. Studies on the influence of hydration on cooking time show that for cereals grains and groats limited hydration is characteristic, accompanied by partial solubilization of polymers.

Due to this, the interaction of water with boiling protopectin and, accordingly, its decomposition into hydrated grains, begins faster. Hydration also promotes a considerable decrease in phytates in cereals and legumes, but did not increase the molar ratio of phytates/Fe and decreased, insignificantly, the molar ratio of phytates/Zn.

\section{Conclusions}

The experimental results showed that:

Whole grains and soriz groats have a cooking time of about 130 and 40 minutes, respectively.

The boiling time of the grains can be reduced approximately 2 times by prehydrating them in water for 8 - 10 hours. For example, for full hydration, at a temperature of $20^{\circ} \mathrm{C}-22^{\circ} \mathrm{C}$, whole grains of corn need 48 hours, those of brown rice-12 ... 28 hours [17].

Hydration media and their concentrations influence the cooking time differently, but optimally, both organoleptic and culinary properties (coefficient of boiling, change in mass, volume) remain water.

Whole grains and sorghum grains are a good alternative in substituting cereals with gluten, in obtaining a wide range of agglutinative preparations with high sensory and nutritional properties.

\section{Acknowledgements}

The research was funded by State Project 20.80009.5107.10, nr. PS-62 "Personalized nutrition and intelligent technologies for my well-being", running at Technical University of Moldova.

\section{Conflicts of Interest}

The authors declare no conflicts of interest regarding the publication of this paper.

\section{References}

[1] World Health Organization (2003) Food Based Dietary Guidelines in the WHO European Region. Nutrition and Food Security Programme WHO Regional Office for Europe.

https://www.euro.who.int/ data/assets/pdf file/0017/150083/E79832.pdf?ua=1

[2] El Khoury, D., Balfour-Ducharme, S. and Joye, I.J. (2018) A Review on the GlutenFree Diet: Technological and Nutritional Challenges. Nutrients, 10, 1410. 
https://doi.org/10.3390/nu10101410

[3] Gaesser, G.A. and Angadi, S.S. (2012) Gluten-Free Diet: Imprudent Dietary Advice for the General Population? Journal of the Academy of Nutrition and Dietetics, 112, 1330-1333. https://doi.org/10.1016/i.jand.2012.06.009

[4] Lerner, A., O'Bryan, T. and Matthias, T. (2019) Navigating the Gluten-Free Boom: The Dark Side of Gluten Free Diet. Frontiers in Pediatrics, 7, 414. https://doi.org/10.3389/fped.2019.00414

[5] Sapone, A., Bai, J.C., Ciacci, C., et al. (2012) Spectrum of Gluten-Related Disorders: Consensus on New Nomenclature and Classification. BMC Medicine, 10, Article No. 13. https://doi.org/10.1186/1741-7015-10-13

[6] Comino, I., Moreno, M.L. and Sousa, C. (2015) Role of Oats in Celiac Disease. World Journal of Gastroenterology, 21, 11825-11831. https://doi.org/10.3748/wjg.v21.i41.11825

[7] Galaiev, O.V., Shevchuk, G.I., Dudchenko, V.V. and Syvolap, I.M. (2011) Molecular Genetic Analysis of Soriz Genome (Sorghum oryzoidum). Cytology and Genetics, 45, 9-15 https://doi.org/10.3103/S0095452711040049

[8] Moraru, G. (2008) Sorghum -A Solution for Ecology, Public Health and the Economy. Buletin informativ - analitic "Inno views" 1.

[9] Siminiuc, R. and Cosciug, L. (2012) The Effect of Dehulling and Thermal Treatment on the Protein Fractions in Soryz (Sorghum oryzoidum) Grains. The Annals of the University Dunarea de Jos of Galati Fascicle VI-Food Technology, 36, 6. https://www.gup.ugal.ro/ugaljournals/index.php/food/article/view/2280/1946

[10] Ратушный, Д.С., Баранов, Б.Д. and Ковалев, Н.И. (2003) Public Catering Production Technology. Physicochemical Processes in FOOD Products during Their Culinary Processing.

[11] Giunti, A. (2012) The Book of Rice and Other Cereals (Il libro del riso ed altri cereali).

[12] Gutium, O., Ciumac, J. and Siminiuc, R. (2017) The Impact of Hydrothermal Treatments on the Texture of Chickpeas. Republic of Moldova, Chisinau

[13] Ozyurt, V.H. and Ötles, S. (2016) Effect of Food Processing on the Physicochemical Properties of Dietary Fibre. Acta Scientiarum Polonorum Technologia Alimentaria, 15, 233-245. https://doi.org/10.17306/J.AFS.2016.3.23

[14] Pedrotti, W. (2003) I cereali. Cereals. Properties, Uses and Virtue. Giunti Demetra.

[15] Sun, K.N., Liao, A. M., Zhang, F., et al. (2019) Microstructural, Textural, Sensory Properties and Quality of Wheat-Yam Composite Flour Noodles. Foods, 8, 519. https://doi.org/10.3390/foods8100519

[16] Medina, W.T., Quevedo, R.A. and Aguilera, J.M. (2013) Changes on Image Texture Features of Breakfast Flakes Cereals during Water Absorption. Food Science and $\begin{array}{llll}\text { Technology International, } & \text { 19, }\end{array}$ https://doi.org/10.1177/1082013212442182

[17] Mincu, I. (1985) Elements of Biochemistry and Physiology of Nutrition.

[18] Taiwo, K.A., Akanbi, C.T. and Ajibola, O.O. (1998) Regression Relationships for the Soaking and Cooking Properties of Two Cowpea Varieties. Journal of Food Engineering, 37, 331-344. https://doi.org/10.1016/S0260-8774(98)00034-X

[19] Ciang, P.-Y. and Yeh, A.-I. (2002) Effect of Soaking on Wet-Milling of Rice. Journal of Cereal Science, 35, 85-94. https://doi.org/10.1006/jcrs.2001.0419 